\title{
Didactic Strategy for Learning and Teaching of Functional Groups in High School Chemistry
}

\author{
Mayra Guadalupe Perez-Rivero ${ }^{1}$, Adolfo Eduardo Obaya Valdivia ${ }^{1}$, Lucila Giamatteo ${ }^{1,2}$, Carlos Montaño-Osorio ${ }^{1}$, \\ Yolanda M. Vargas-Rodríguez ${ }^{1 *}$
}

${ }^{1}$ Department of Chemical Science, FES-Cuautitlán UNAM, MADEMS (Chemistry), México, 2Instituto Tecnológico y de Estudios Superiores de Monterrey, México

*Corresponding Author: ymvargas@unam.mx

\section{ABSTRACT}

With the aim of improving the teaching and learning of chemistry functional groups, a didactic strategy was designed based on real-life situations. This strategy was used at the high school level, in the subject of "Chemistry II." One group of students was taught functional groups using interactive board software through different dynamics (experimental group), and another group was taught traditionally (control group). Learning was evaluated through a series of questions, exercise solving, and scientific problems. Results indicate that the group of students in which the interactive board software was used achieved higher learning levels in comparison to the control group, which was traditionally taught.

KEY WORDS: chemistry; didactic strategic; functional groups; interactive board

\section{INTRODUCTION}

W

Then students learn organic chemistry, they are frequently overwhelmed by the amount and complexity of the information that they are supposed to acquire (Knudtson, 2015). Particularly, organic chemistry encompasses an enormous variety of organic compounds. Hence, these compounds are grouped into "functional groups" since each functional group provides specific chemical properties and applications (Atkins and Jones, 2006). Learning and teaching of functional groups in high school has traditionally been driven in a memoristic way in which the examples of organic compounds are usually molecules that students have never heard of. This approach does not allow for students to apply this knowledge in other topics, such as chemical reactions, therefore, often becoming frustrating for both students and teachers (Byrd and Hildreth, 2001).

Problem-based learning (PBL) has as a basis of the following principles. Learning is constructed based on the knowledge that students have (Woods, 1994). In PBL, students learn by working and researching in groups. The teacher performs the role of facilitator or guide accompanying the students; as such, the teacher's role is far from the master (Edens, 2000). Similarly, learning is based on situations relevant to the student's world.

The context of learning in PBL is essential for the formation in the student the following objectives. First, work motivation of students in increased as students work in groups on problems or on projects (Cowden and Santiago, 2016). Second, enhanced development skills that will be required in the future world of students (Savery, 2006). Additional areas of student development through PBL are as follows: The development of intelligence and the personal style of each student; focus on the personal capacity of learning to develop a students' learning to learn; working in a social environment; working through conflict to stimulate students' learning; and supporting the skills needed for students to learn to evaluate own learning (Bhattacharyya, 2005; Hofstein and Kesner, 2006). The implementation of real-life chemistry problems provides a wide variety of interesting topics for students (Flynn and Biggs, 2012; Hicks and Bevsek, 2012; Al-Salihi and Alobaidi, 2018; Obaya et al., 2018).

On the other hand, information and communication technology (ICT) tools are constantly being renovated and invented. These tools help facilitate the teacher's work as they open up to the teacher a huge range and variety of information and technological resources (Gurses et al., 2015; Moutinho et al., 2015). This allows classrooms to be transformed and supports students' learning. One such tool is the interactive board (Talanquer, 2009; Mata and Lazar, 2016).

In this study, a didactic strategy is presented to improve the teaching and learning of functional groups. The molecules that were selected contain products of common use in daily life (such as ethyl alcohol, citric acid, and acetylsalicylic acid). Finally, this study included the use of a didactic tool for the SMART Notebook software.

\section{DEVELOPMENT}

The aim of this study was to design and apply a didactic strategy based on real-life problems using an interactive board 
to improve learning and teaching of functional groups to high school chemistry students. To achieve this, the work was divided into three phases: The strategy design, the application of the strategy to the experimental group, and the traditional teaching for the control group.

\section{Scientific Analysis}

Academic content was analyzed for where functional groups are studied. For this study's Normal High School in Cuautitlán Izcalli, Estado de México, it is in the class "Chemistry II." In this class, students would be exposed to the following: Hydrocarbons, functional group concept, and structural formulas of the most common functional groups (hydroxyl, carbonyl, carboxyl, ester, amine, and amide) which characterize alcohols, ketones, aldehydes, carboxylic acids, esters, amines, and amides, respectively.

1. Didactic analysis: Students' cognitive characteristics were studied, including their attitude toward the topic, the subject, and science to gain an understanding of their interest and motivation; directing this toward the topic and relating it to real-life topics as food, medicine, biomolecules, and petrochemical derivatives to generate the didactic material.

2. Didactic material elaboration: A digital presentation was designed with the topic of hydrocarbons and functional groups, as well as interactive activities to reinforce learning. Moreover, a compendium was created named "functional groups card" with general information about the functional groups that would be studied, their molecular structure, the way they originated from a hydrocarbon, the family they belonged to and their application in commercial products (Appendix 1).

a. ICTs used by the teacher: Chemsketch software, ChemSpider software, computer, SMART Notebook software, and projector.

b. ICTs used by the students: Computer, SMART Notebook software, and projector.

3. Evaluation instrument: To evaluate the effectiveness of the designed didactic strategy, an evaluation instrument was designed (Appendix 2) with four learning dimensions as shown in Table 1 (Marzano, 2001).

\section{Sample Population}

Two groups of the $3^{\text {rd }}$ year students (students aged 16-17) from the Normal High School in Cuautitlán Izcalli, México, who were enrolled in the Chemistry II subject participated. The first group consisting of 31 female and 26 male students was taught using the interactive board software through different dynamics; this group was the experimental group. The control group had 31 female and 20 male students and was taught using traditional methods (i.e., board and markers).

\section{Strategy Application on the Experimental Group}

It is important to know that there was no interactive board available in the Normal High School, so only the SMART Notebook software was used according to the following plan:

1. Theory on the topic of functional groups was taught to students through a digital presentation using the didactic tools from the SMART Notebook software, where theoretical concepts regarding hydrocarbons (aromatic and aliphatic), classification, and molecular structure were presented. A slide example is shown in Figure 1.

2. After that, the teacher described the characteristics of the functional groups, the families they make up (alcohols, ketones, aldehydes, carboxylic acids, esters, amines, and amides) and their applications in commonly used products as shown in the example (Figure 2).

3. Interactive activities: To promote discussion of the learned concepts among students, different activities were designed with the use of the interactive board software. Some of these are described below:

a. Functional group identification in molecules present in food (citric acid), medicine (amphetamine and paracetamol), and commercial products (colorants). These are shown in Figures 3 and 4. The interactive activities took place as a group, where students came to the front to select the functional group and enter their response with the computer's keyboard. When the functional group was selected, the software assessed their answer by showing a tick or a cross. In the case of colorants, when students clicked, the functional group's name was shown in a pop-up box.

b. Superclassification: This interactive activity was handled similarly to the one described before. Students selected the chemical structures that were found on the bottom of the slide and took them to the spiral that corresponded to the selected group. If the structure did not belong to the group, it is returned back to its place (Figure 5).

\section{Real-life Problem-solving}

Real situation problems were formulated where the student proposes solutions as a scientist for active ingredient synthesis like the acetylsalicylic acid (Figure 6).

1. By the end of the session, a debate on the importance of functional groups in a daily life basis was carried out.

2. Finally, the evaluation shown in Appendix 2 took place individually.

\begin{tabular}{lll}
\hline \multicolumn{2}{l}{ Table 1: Learning dimensions of the evaluation reagents } & Items \\
\hline Learning dimensions & Learning indicator & Open answer questions (1,2,3) \\
\hline 1 & Knows or retrieves the concept, classification, and properties of the functional groups & Sentence completion $(4,5,6,7,8)$ \\
2 & Understands the position of atoms in the functional groups & Scheme identification $(9,10,11)$ \\
4 & Analysis the concepts to identify the functional groups in chemical molecules & Scientific problem-solving (12) \\
\hline
\end{tabular}




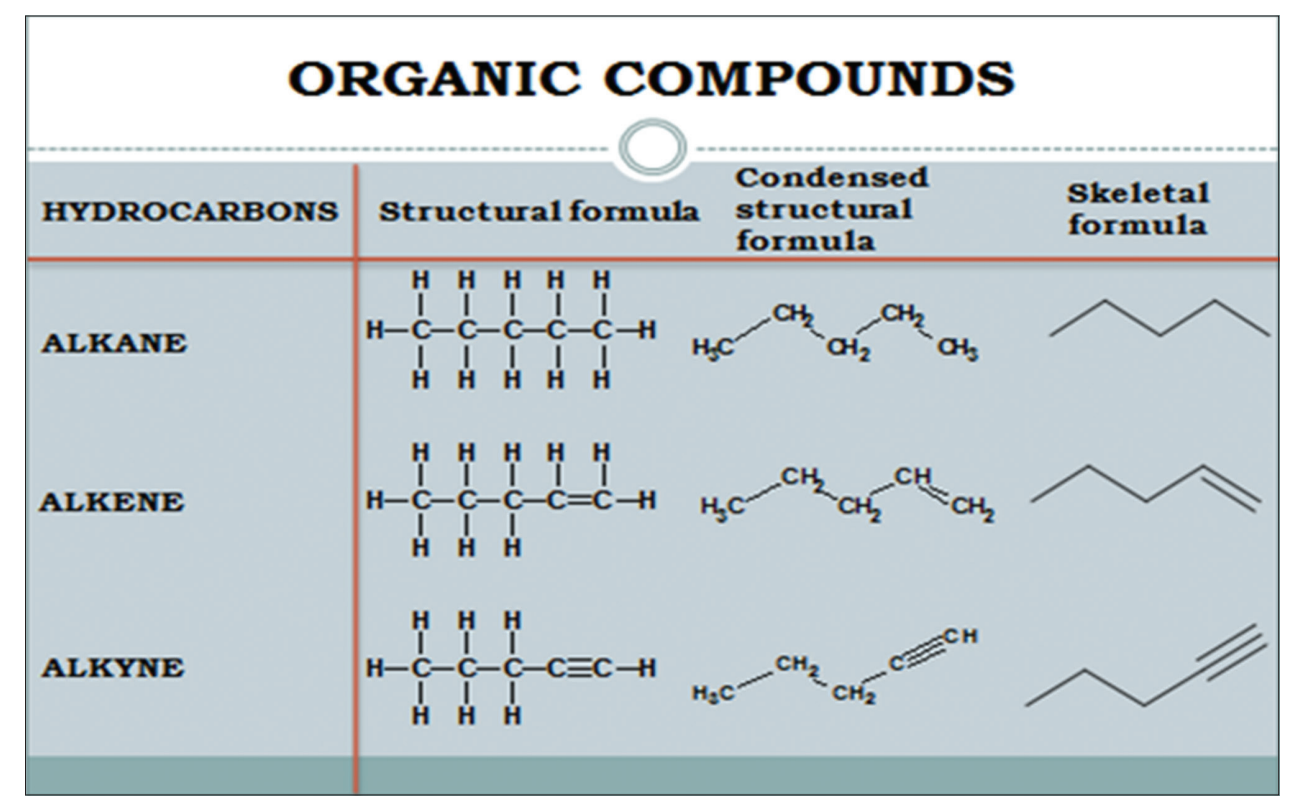

Figure 1: Hydrocarbons

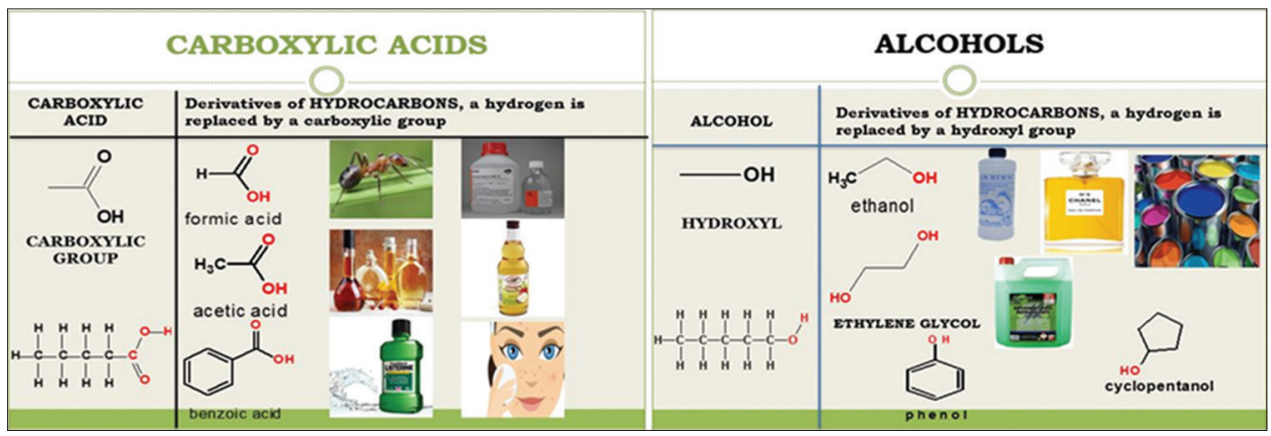

Figure 2: Functional groups in commonly used products
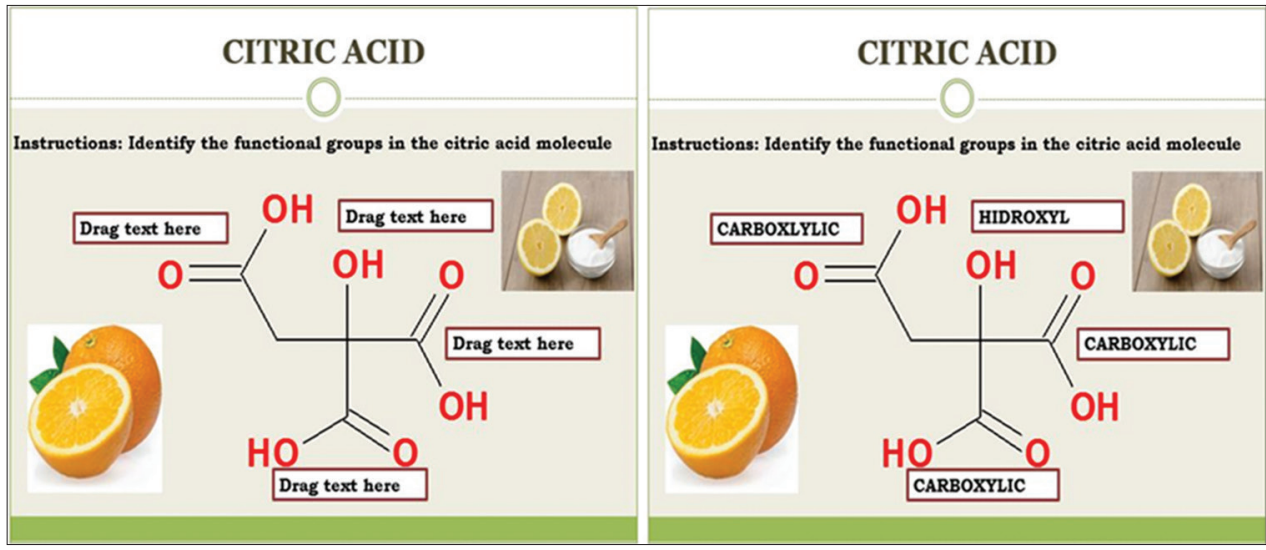

Figure 3: Functional groups in food

\section{Strategy Application on the Control Group}

The study of functional groups for the control group was approached memoristically and focused on learning properties and characteristics of the functional groups, without real-life examples. The tools used were board and markers. The same evaluation (Appendix 2) was applied to students.

\section{RESULTS}

After applying the strategy for learning and teaching functional groups using the interactive board software and applying the final evaluation to both the experimental and control group, the evaluation instrument was graded. Figure 7 shows a 


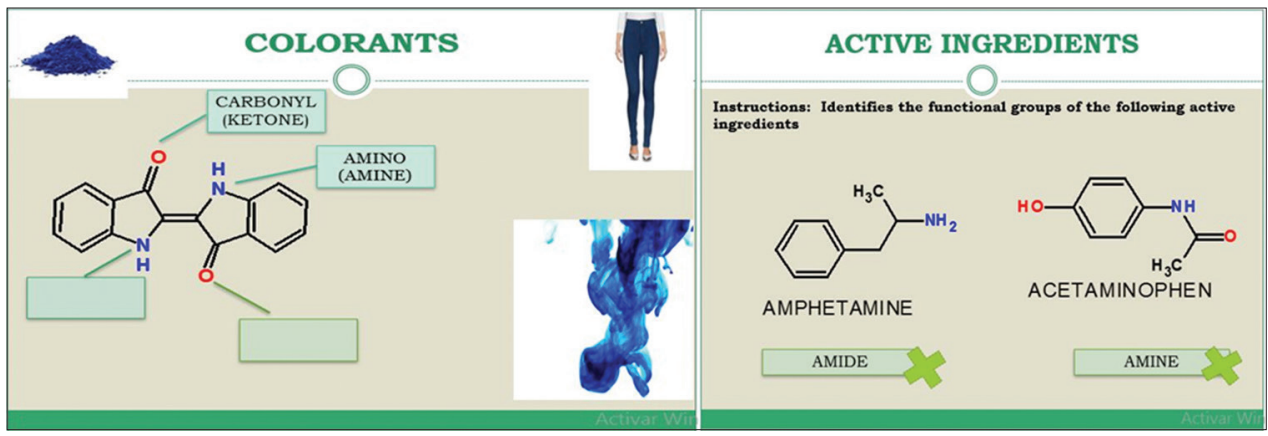

Figure 4: Functional groups in active ingredients and colorants

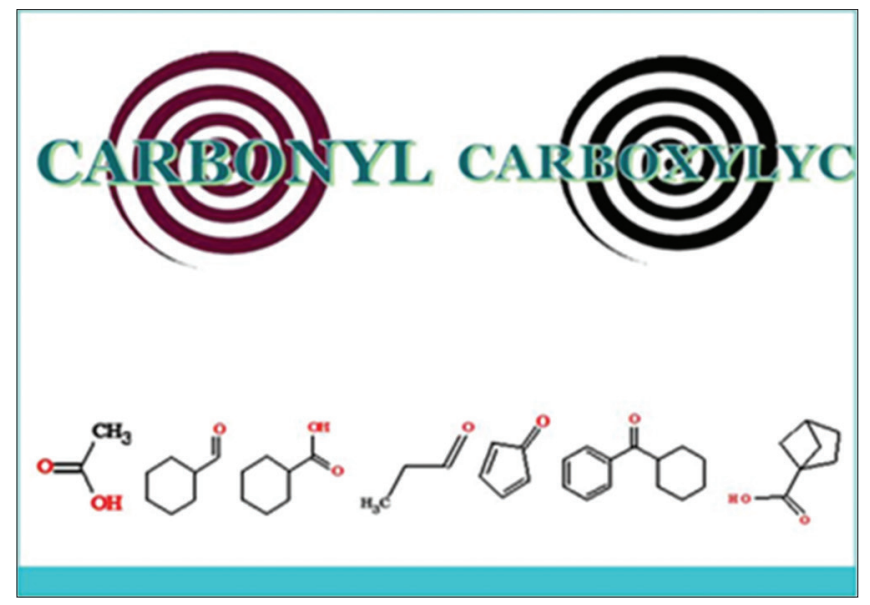

Figure 5: Functional group superclassification

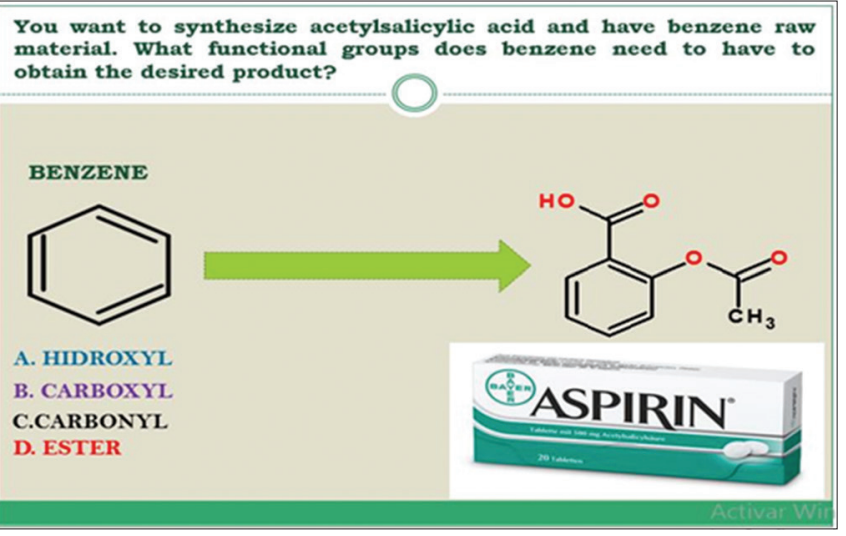

Figure 6: Acetylsalicylic acid synthesis

fragment of the examination belonging to two students from the experimental group.

Correct answers were clustered for each group and with the obtained results, a bar graph was made (Figure 8) - It must be noted that items 1,2 , and 3 relate to learning level 1 , which corresponds to knowledge "recovery" (Table 1). When comparing the answers between the control group and the experimental group, it was observed that the control group got $25 \%$ of correct answers where the experimental group got $71 \%$ of the answers correct. This would seem to indicate that the experimental group acquired more knowledge recovery

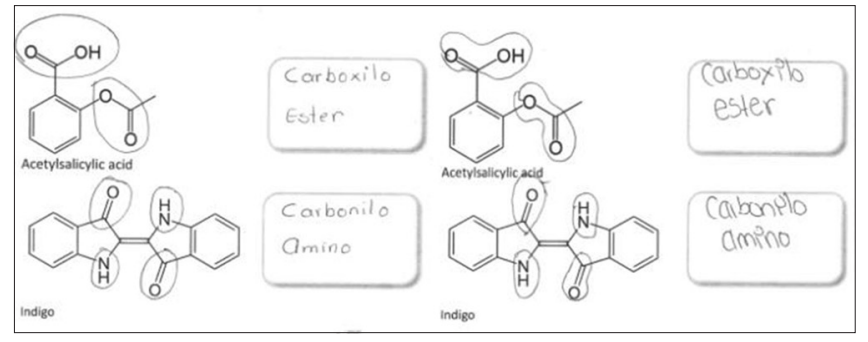

Figure 7: Examples of items answered by students in the experimental group

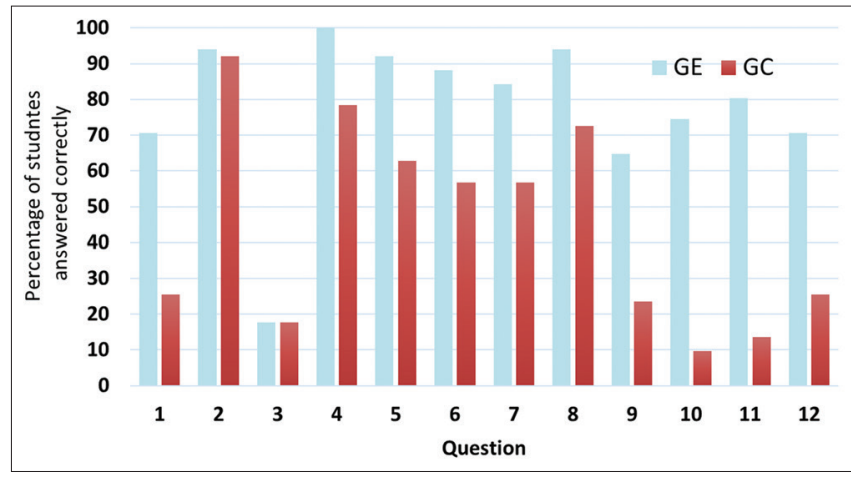

Figure 8: Learning levels evaluation

of a functional group. In reference to the classification of functional groups (item 2), significant advances were obtained in both groups given that $94 \%$ of students in the experimental group and $92 \%$ in the control group answered correctly, showing an effective result for both approaches. When asking "Which properties are present in organic compounds of certain material or commercial products that enable us to give them a specific use or application?" (Item 3 ) in both groups $18 \%$ of correct answers was obtained, a poor result associated to the fact that the question was not posed correctly.

In the items from learning level $2(4,5,6,7$, and 8$)$ in which understanding to identify atoms and the position of these in functional groups, it was observed that the experimental group had a higher percentage of correct answers in all the items: $100 \%, 92 \%, 88 \%, 84 \%$, and $94 \%$ compared to the results obtained in the control group: $78 \%, 63 \%, 57 \%$, $57 \%$, and $73 \%$, respectively. The percentage of correct 
answers from the experimental group compared to the control group was significantly better for all items. This also would seem to indicate that a better understanding of atoms conformation in functional groups was achieved by the experimental group.

In terms of correct results to items 9,10 , and 11 for the experimental group, $65 \%, 75 \%$, and $85 \%$ were obtained, respectively, compared to $24 \%, 10 \%$, and $14 \%$ for those of the control group. These items belong to level three, indicating that most students from the experimental group were able to analyze and to identify the functional groups present in chemical molecules.

Finally, it was observed that the percentages of correct answers in item 12 in the experimental and the control group were $71 \%$ and $25 \%$, respectively. It is important to notice that this item corresponds to level 4, which shows that with the applied strategy and the ICT tools in the experimental group, students were able to acknowledge and apply knowledge in a real problem.

\section{CONCLUSIONS AND CONTRIBUTIONS OF THE WORK}

With the aim of improving learning and teaching of functional groups at a high school level, a strategy based on real-life situations was designed and applied, using an interactive board software as a tool for both theory explanation and interactive activities made by students.

The four dimensions of recognition, comprehension, analysis, and application were evaluated. As a conclusion, the applied strategy and the use of ICTs allowed participants to achieve higher levels of learning when compared to those experiencing more traditional teaching. This strategy can be used for learning and teaching of functional groups in high school. However, with the applied strategy and using the interactive board software, students acquire the different learning levels: Recognition, comprehension, analysis, and application related to functional group knowledge. As a conclusion, the applied strategy and the use of ICTs allowed participants to achieve higher levels of learning when compared to those experiencing more traditional teaching. This strategy can be used for learning and teaching of functional groups in high school.

\section{ACKNOWLEDGMENTS}

The authors would like to thank Designer Suemi Lima Vargas for editing the figures and Masters in Teaching Guadalupe Iveth Vargas-Rodríguez for your technical assistance.

\section{REFERENCES}

Al-Salihi, F.G., \& Alobaidi, A.H. (2018). Problem based learning (PBL) in organic chemistry. International of Journal of Medical Science, 1(2), 64-70.

Atkins, P.W., \& Jones, L. (2006). Principios de Química: Los Caminos del Descubrimiento. México: Edición Editorial Médica Panamericana.

Bhattacharyya, G. (2005). A cultural approach to problem solving. Educación Química, 16(2), 222-229.

Byrd, S., \& Hildreth, D.P. (2001). Learning the functional groups: Keys to success. Journal of Chemical Education, 78(10), 1355-1357.

Cowden, C.D., \& Santiago, F. (2016). Interdisciplinary explorations: Promoting critica thinking via problem-based learning in an advanced biochemistry class. Journal of Chemical Education, 93(3), 464-469.

Edens, K. (2000). Preparing problem solvers for the $21^{\text {st }}$ century through problem-based learning. College Teaching, 48(2), 55-61.

Flynn, A.B., \& Biggs, R. (2012). The development and implementation of a problem-based learning format in a fourth-year undergraduate synthetic organic and medicinal chemistry laboratory course. Journal of Chemical Education, 89(1), 52-57.

Gurses, A., Digar, C., \& Geyik, E. (2015). Teaching of the concept of enthalpy using problem based learning approach. Procedia Social and Behavioral Sciences, 197(25), 2390-2394

Hicks, R.W., \& Bevsek, H. (2012). Utilizing problem-based learning in qualitative analysis lab experiments. Journal of Chemical Education, 82(2), 254-257.

Hofstein, A., \& Kesner, M. (2006). Industrial chemistry and school chemistry: Making chemistry studies more relevant. International Journal of Science Education, 28(9), 1017-1039.

Knudtson, C. (2015). ChemKarta: A card game for teaching functional groups in undergraduate organic chemistry. Journal of Chemical Education, 92(9), 1514-1517.

Marzano, R.J. (2001). In: Guskey, T.R., (Ed.), A New Taxonomy of Educational Objectives. Experts in Assessment Series. Thousand Oaks, CA: Corwin.

Mata, L., \& Lazar, G.L.I. (2016). Interactive whiteboards for teaching and learning science: Ascertaines research. Journal of Innovation in Psychology, Education and Didactics, 20(2), 135-148.

Moutinho, S., Torres, J., Fernandes, I., \& Vasconcelos, C. (2015). Problembased learning and nature of science: A study with science teachers. Procedia Social and Behavioral Sciences, 191, 1871-1875.

Obaya, A., Vargas-Rodríguez, G.I., Lima-Vargas, A., \& Vargas-Rodríguez, Y.M. (2018). Problem-based learning: In what time does pasteurized milk at room temperature break down? Chemical Education, 29 (1), 99-109.

Savery, J. (2006). Overview of problem-based learning: Definitions and distinctions the interdisciplinary. Journal of Problem Based Learning, $1(1), 9-20$.

Talanquer, V. (2009). De escuelas, docentes y TICs. Educación Química, 20(3), 345-350.

Woods, D.R. (1994). Problem-Based Learning: How to Gain the Most from $P B L$. Ontario: Waterdown. 


\section{APPENDICES}

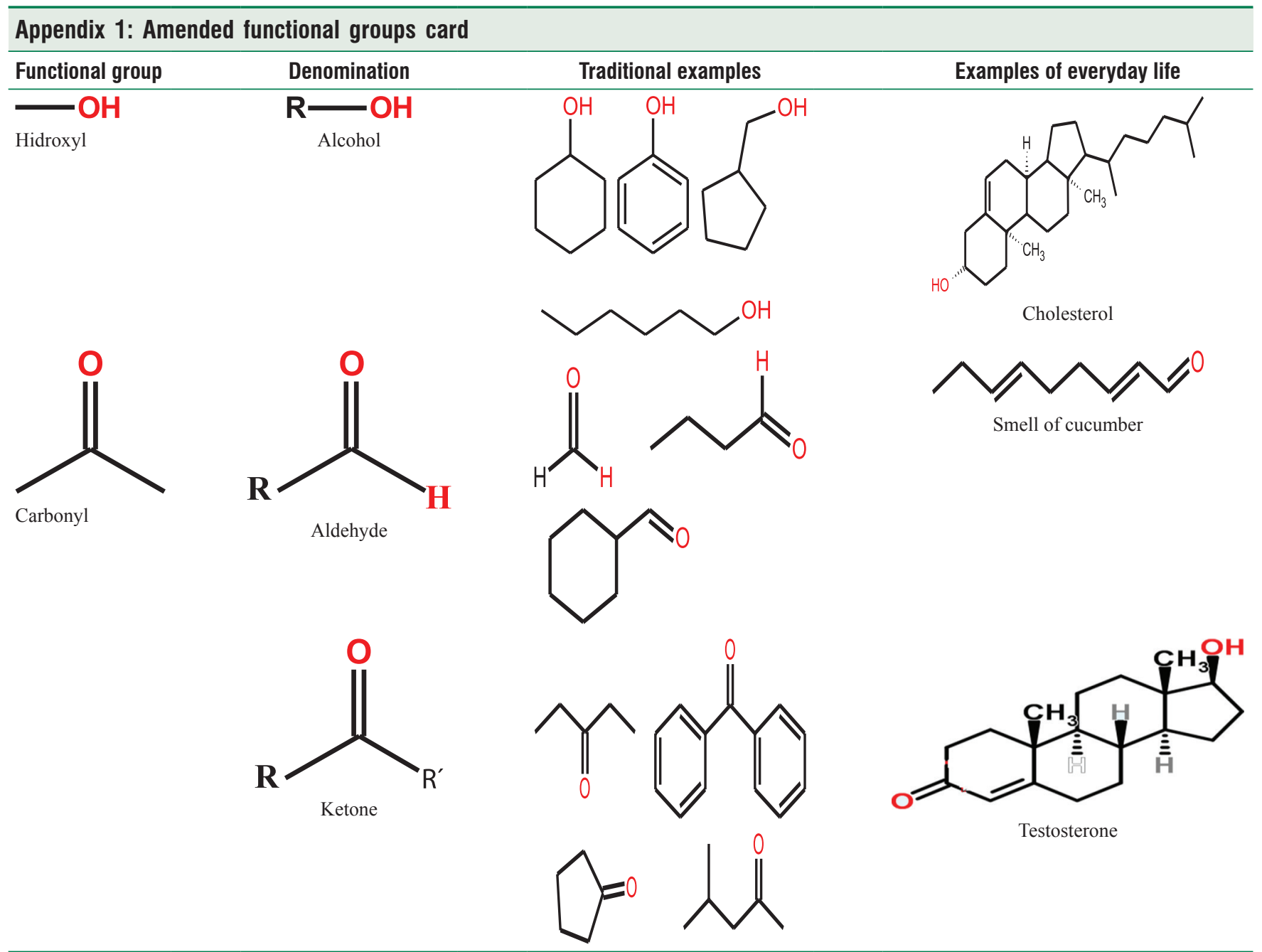

\section{Appendix 2: Amended functional groups evaluation}

I. Instructions: Answer the following questions

1. What is a functional group?

2. What are the functional groups?

3. What properties do organic compounds have of certain commercial materials or products that allow us to give them a specific use or application?

II. Instructions: Place the word needed to complete the statements (ester, amide, ketone, hydroxyl, amines, and aldehydes) in the underlined spaces.

4. Alcohols are derivatives of hydrocarbons in which one or more hydrogens are substituted by the group

5. The and they are organic compounds that contain the carbonyl group. In the , the carbonyl group has at least one hydrogen atom attached, and in the , the carbonyl group is surrounded by carbon atoms.

6. Esters are compounds in which the group it is surrounded by carbon atoms.

7. Amides are organic compounds whose functional group , it is attached to hydrogen atoms and carbon atoms.

8. The they are organic nitrogenous compounds and are composed of the amino group attached to hydrogen atoms or carbon atoms. 
III. Instructions: Identify all functional groups (hydroxyl, carbonyl, carboxyl, ester, amino, and amide) for each of the following organic compounds.

9.

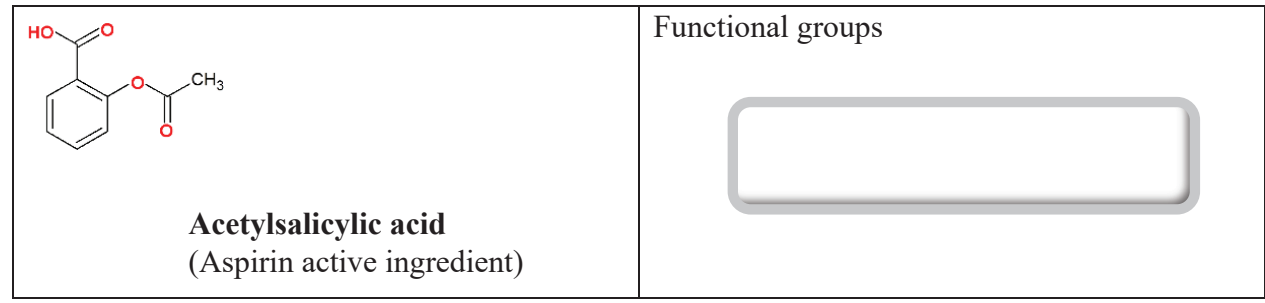

10.

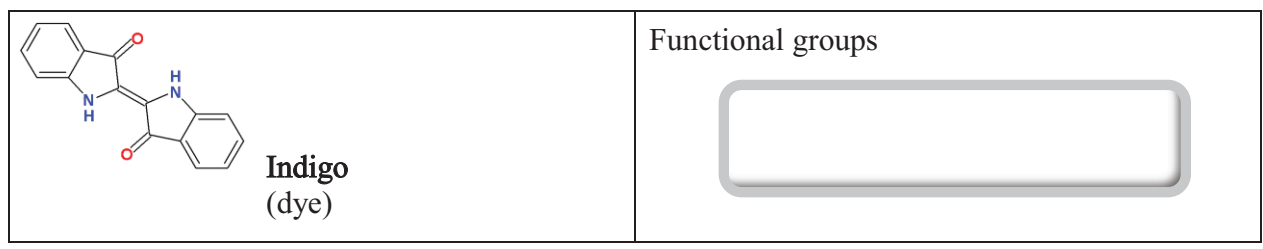

11.

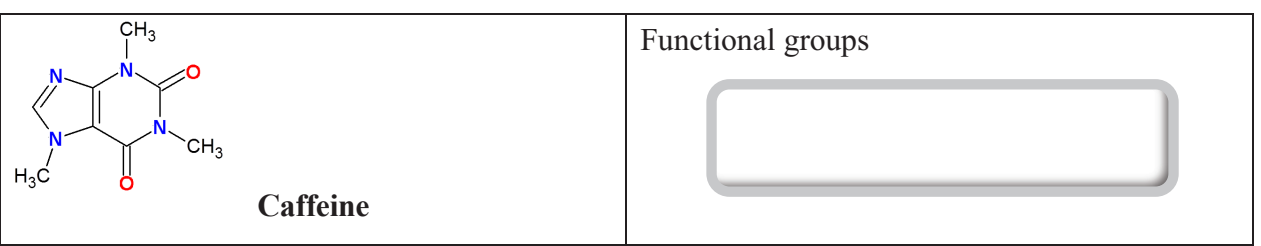

12. You need to synthesize paracetamol and have benzene as the raw material. What functional groups should benzene have to obtain the desired product?

Benzene

